\title{
Research on the Electricity and Information Technology Class Specialized Course Curriculum Reform for Universities
}

\author{
Wen Zhun Huang ${ }^{\mathrm{a}}{ }^{*}$, Xin Xin Xie ${ }^{\mathrm{b}}$, Yu Ting Zhang ${ }^{\mathrm{c}}$ and Shan Wen Zhang ${ }^{\mathrm{d}}$ \\ Department of Electronic Information Engineering, Xijing University, Xi'an 710123, China \\ ahuangwenzhun6@126.com, b346148500@qq.com, '912482316@qq.com, dwjdw716@163.com
}

Keywords: Course Curriculum Reform; University Course Management; Electricity and Information Technology (EIT); Computing Thinking.

\begin{abstract}
With the bursting development of electricity and information technology, the reform of course curriculum for university students is urgently needed. Domestic science and engineering universities are generally open circuit principle, circuit principle experiment, analog electronic technology, analog electronic technology, digital electronic technology, digital electronic technology experiment technology foundation course, objects and research problems of these courses are geared to the needs of electronic electrical engineering environment, the relevant follow-up courses need circuit and a solid knowledge of electronic circuit and so on. In this paper, we review the state-of-the-art patterns of teaching for EIT related courses. The proposed pattern will largely enhance the effectiveness of the current teaching pattern and gain satisfactory result for the future generation.
\end{abstract}

\section{Introduction}

Domestic science and engineering universities are generally open circuit principle, circuit principle experiment, analog electronic technology, analog electronic technology, digital electronic technology, digital electronic technology experiment technology foundation course, objects and research problems of these courses are geared to the needs of electronic electrical engineering environment, the relevant follow-up courses need circuit and a solid knowledge of electronic circuit, etc. At present, the domestic electricity class foundation course teaching system basically adopt the mode of "serial", course of general path from "circuit principle", "analog circuit", "digital circuit", "signals and systems", "electromagnetic field" order, even there are strict in AP requirements. Various curriculum standard content system which is consist of a standard class arrangement, and by their courses and teaching materials construction organization (research) to a unified discussion arrangement [1-5]. Course, therefore, their form is complete but relatively closed system of knowledge, the cohesion and connection between each other is not tight, using the theory of system analysis and design method and different in style. Circuit model and the actual devices such as the research object is often points on courses to group classes, according to the traditional way to spread out the basic concept in circuit and analog electronic technology course teaching system may bring about the students. Various curriculum construction and implementation independently of each other, resulting in "teaching more and more, less and less" church, "fragmentary knowledge more and more, relevance of thinking ability is more and more weak". Sui generis course, the more the students' learning style is easy to lead to give priority to with convergent thinking [6-8].

Foreign technology foundation course content covers basic but very broad, and often take the analysis and design, the combination of theory and practice of teaching methods, analysis and design in each knowledge unit title, homework and experiment have design problems. At home of course, because the content is pure and partial theory and idealized, design subject difficult to arrange. Therefore, the construction of a harmonious and unified knowledge system, concise teaching content, in an appropriate manner to guide students independent learning, positive thinking, arouse the enthusiasm for the practice innovation is urgent [9-12]. In this paper, we conduct research on the 
electricity and information technology class specialized course curriculum reform for universities. The detailed discussed will be introduced in the following sections.

\section{The Computational Thinking and Basic Computer Teaching Reform}

Understanding of the "Computing Thinking". The word "computing thinking" is not strange, many scholars and experts in various occasions and stress calculation thinking ability training is not ignored. In March 2006, the head of the department of computer science at Carnegie Mellon university weeks to really (professor Jeannette $\mathrm{m}$. Wing) in the journal of the American computer authority Communications of the ACM, and defined the Computational Thinking (Computational Thinking) : Thinking is calculated by using the basic concept of the computer science problem solving, system design and the understanding of human behavior covers computer science and the breadth of a series of Thinking activity. This article has caused great repercussions at home and abroad, also caused the field of computer education on thinking ability training of great concern and attention. The ministry of education of institutions of higher learning basic computer courses teaching steering committee, director of the committee member of Chen explicitly put forward to strengthen the "computing thinking" oriented computer basis teaching, and on the basis of the computational thinking oriented computer teaching seminar made clear that computational thinking is the basic computer course reform inevitable question, is this the computer foundation teaching faces new challenges, and opportunities. Obviously, the importance of education basic computer teaching in the university as a whole more prominent, basic computer teaching is to cultivate with modern spirit and science thinking ability is one of the three major compulsory courses (the other two as mathematics, physics).

In-Depth Analysis on "Computing Thinking". How to understand the real meaning of computational thinking, however, we need to seriously think about and to learn, especially thinking what is the smallest components, how to construct? These educators need to continue to learn, and gradually formed. The author thinks that, its core is to change education idea, from teaching content to teaching method and means will be integrated into the teaching of thinking, subtly trains the student to build basic computer literacy thinking ability, learning ability and research ability. Calculation of weeks to really think that thinking is a way of human to solve the problem, but it is by no means to make the human to think like computers. Computer dull and dreary, human intelligent and imaginative, is human to computer. Configuration computing devices, we can use our wisdom to solve those problems before the time of calculation did not dare to try, realize "less than" is only limited by region. Computational thinking is the essence of abstraction and automation, it is like everyone have the ability to "read, write, calculate", must have the ability of thinking. These thoughts and recognize the importance of words embody the ability to build and develop thinking and original.

The Direction of the Basic Computer Teaching Reform. In recent years, how to introduce the computational thinking in university computer foundation teaching course, experts and scholars made a lot of discussion. Jiaguang sun academicians pointed out in the context of the transformation of the computer science (computer science) one of the most fundamental and long-term ideas is the "computing thinking", many scholars believe that it is computer science and computer science in the recent ten years the most important academic thought has the fundamental and long-term. Thinking is calculated by using the basic concepts of computer science to solve problems, design system, and understanding human behavior. Chen guoliang academician, Li Lian professors and other experts and scholars think, calculate thinking ability training is composed of a series of courses, the course "fundamentals of computer" is the most important training computational thinking is also one of the best courses. To sum up, computer basis teaching is an important link in cultivating college students' computer literacy, introducing computational thinking teaching reform on the course of "fundamentals of computer" is very important and urgent. This is a challenge to the traditional computer basis 
teaching, center of gravity is the change of education teaching idea, teaching content, teaching methods and means of innovation.

\section{The Practical and Feasibility Analysis for the Reform}

Overview of the Perspective. Electrical technology base core curriculum teaching process including both theoretical teaching and experimental teaching link, the cooperation between the two links is every time after completing certain content theory teaching, followed by the related experiments. The main purpose of the experiment course is validation, deepen understanding of the content of the theory and master the use of conventional instruments and equipment. To deepen the understanding of and consolidate learning content is necessary, but the experiment content is often accounts for the vast majority of verification. In addition, the laboratory is according to the curriculum, is a department management, teaching and research section and laboratory are independent of each other, also are independent of each other, between laboratory and laboratory experimental teaching status and has not been seriously, lack of incentive mechanism. Such long time inevitable experiment equipment utilization rate is low, severe resource waste, also does not help the cultivation of innovative talents. In order to solve the above problems, the practice teaching reform, make the LABS open separate class, teaching process combined with the simulation experiment of physical experiment, encourage students to participate in various extracurricular activities of science and technology, pay attention to the cultivation of engineering practice ability.

Physical Experiment Combined with Simulation Experiments. "Nakedness and used, to strengthen the theory with practice" is a direction of electricity class foundation course reform. The actual situation and is refers to the actual operation combined with experiment and computer simulation. Through the physical experiment can make students come into contact with all kinds of actual power equipment, to master the use of conventional instrument and physical experiment for the verification experiment, through the physical experiment can deepen students' understanding of basic theoretical knowledge, through hands on the attachment, also can improve the students' practical ability. So, electricity class technical basic course of physical experiment link must be retained. But more than the physical experiment process for teachers to prepare the good experimental instrument, experiment, students need to do is in the know the experimental principle correctly under the condition of instrumentation, the measured experimental data, therefore, this lack of students' active thinking and the cultivation of the students' practical ability and engineering practice ability. In order to solve the above problem, at the same time of developing physical experiments, increase comprehensive, designing experiments. Electricity core technology foundation course content coverage, the mutual penetration, the content of the course can fuses in together, make the electricity class technology base core curriculum design, content and direction of comprehensive experiments can include many. Enable students to combine their major direction, fully apply basic knowledge of technology. Effectively arouse the enthusiasm of students, the student subjective initiative and creativity into full play.

Module Structure of Experiment Content. Electrical technology based on the core courses for independent class, its content is not a separate experiment, but a comprehensive content of the courses of a series of experiments. Series of experiment can be divided into primary module, intermediate and advanced module. Primary module mainly is to validate model experiment and the design of simple model experiment, this part can be finished within the prescribed period. Intermediate module in the experiment are all designed experiment, its difficulty is greater than the primary module design type of experiments, the main students able to skillfully use all kinds of electronic design tools and all kinds of instruments and meters, and can choose the right in the process of experiment is good design. This level of experimental project choice, should not be limited to the unit circuit and the design of the single function, but based on the small electrical, electronic and control system design. Some of the content of the subject may be students didn't study, perhaps is the interdisciplinary, which requires the 
student information query and put forward the design scheme, implementation method, the required equipment and components and model, the number of teachers' approval, can start experiment, experiment has been completed, write the report design. This part can be dispersed in one semester or one school year. Advanced module experiment project belongs to the comprehensive experiment item which can adopt the way of practice and course design, concentrated to complete within 3 weeks.

Support for Students to Participate in Various Extracurricular Activities. Through the rich and colorful extracurricular activities of science and technology, not only increase students' interest in learning class technology foundation course, but also improves the students' practical ability, to enhance the students' innovation consciousness and entrepreneurship. The following 5 parts introduce the ideal in detail. (1) In electronic design competition, knowledge competition, skills competitions, subject contests, sports competitions and as the main body of the design, such as mathematical contest in modeling competition. (2) Written in science and technology production, scientific research report, academic papers published and held seminar content as the main body of scientific research. (3) To develop the teaching of multimedia courseware, independent design experiment, organizing classroom lectures, guidance, etc. as the main body and teaching research and development of the content. (4) To the computer level certificate, certificate of professional skill levels, the patent certificate and special skills, etc. Act as the main body of the certificate content. (5) Science and technology innovation practice activities, science, academic week, reading month and held the exhibition activities such as scientific and technological achievements, create opportunities, absorb more students to participate in activities.

\section{Summary and Conclusion}

At present, the domestic electricity class foundation course teaching system basically adopt the mode of "serial", course of general path from "circuit principle", "analog circuit", "digital circuit", "signals and systems", "electromagnetic field" order, even there are strict in AP requirements. Various curriculum standard content systems which are consist of a standard class arrangement, and by their courses and teaching materials construction organization to a unified discussion arrangement. Wide coverage of the electricity class technology foundation course content, and focus on application, is to cultivate students geared to the needs of engineering practice ability, innovation consciousness is the important content, is to implement "a real two gen" talent training in our school characteristics is important one annulus. Therefore, electricity class technology foundation course teaching method reform and practice, through constantly draw lessons from advanced experience at home and abroad, further perfecting the technology foundation course construction and its corresponding teaching reform, is advantageous to the more high quality talents cultivation of innovative technology. The reform introduced by this paper will largely enhance the effectiveness of the current teaching pattern and gain satisfactory result for the future generation.

\section{Acknowledgements}

This work was supported by the project "The 12th five-year education science plan project of Shaanxi Province (SGH13465)". The authors wish to thank the Shaanxi Province Education Science Planning Leading Group Office for their help.

\section{References}

[1] C. J Kobus: ASME heat transfer conference (Minneapolis, US, 2013), p.V004T16A001.1.

[2] R. Green, M. J. Benton and M. C. Schlairet: Nurse Educator, Vol.39 (2014) No.6, p.321. 
[3] Z. M. Zhang: International Conference on Information, Electronics and Computer (Wuhan, China, 2014), p.157.

[4] X. D. Yie: Journal of Yibin University, Vol.13 (2013) No.6, p.110. (In Chinese)

[5] S. McMahon, J. L. Postmus and C. Warrener: Journal of Social Work Education, Vol.49 (2013) No.2, p.307.

[6] R. Higgins, P. Hogg, L. Robinson: Radiography, Vol.19 (2013) No.1, p.62.

[7] X. L. Ma, G. Q. Zhao and T. Wu: Journal of Distance Education, Vol.31 (2013) No.1, p.79. (In Chinese)

[8] E. Sengel: Journal of the Balkan Tribological Association, Vol.20 (2014) No.3, p.488.

[9] Jiri Kratochvil: The Electronic Library, Vol.32 (2014) No.3, p.322.

[10] M. Belfiore, M. Pennisi, G. Aricd, S. Ronsisvalle and F. Pappalardo: Biomed Research International, Vol.2014 (2014) No.13, p.371809.

[11]C. C. Chang: Library Management, Vol.34 (2013) No.1-2, p.40

[12] R. B. Krishnan, N. K. Sakthivel: Research Journal of Applied Science, Engineering and Technology, Vol.4 (2012) No.10, p.1343. 